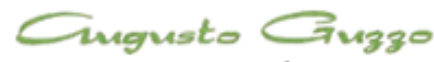

REVISTA ACADEMICA

\title{
Sintonia entre teoria e a prática no ensino de língua inglesa nos parâmetros curriculares nacionais
}

\author{
Liliana Covino' \\ Recebido em: 09/02/2013. Aprovado em: 13/03/2013. Disponibilizado em: 26/06/2013
}

1. Liliana Covino é Mestre, Professora do Curso de Letras Inglês/Português da Faculdade ENIAC São Paulo. Leciona a disciplina de Prática de Ensino de Língua Inglesa e Estágio Supervisionado.

\section{Resumo}

O Ministério da Educação lançou, em 1998, um documento com orientações didáticas e pedagógicas para que os professores adotassem um novo sistema de ensino, tornando-o mais relevante e significativo para o aluno: Os Parâmetros Curriculares Nacionais (PCNs). Eles sugerem que os professores adotem uma abordagem sociointeracional para o ensino da língua estrangeira. Como professora do curso de Letras Português/Inglês de instituição de ensino Superior da Grande São Paulo, lecionando a disciplina de Prática de Ensino e Estágio Supervisionado de Língua Inglesa, a pesquisadora sentiu a necessidade de um estudo mais aprofundado para, ao entender melhor a questão, poder implementar melhorias em sua própria prática docente. Sendo assim, essa pesquisa tem como objetivo verificar até que ponto a prática docente dos professores de Língua Inglesa, nas escolas de ensino fundamental da Grande São Paulo, se aproxima do preconizado pelo documento "Os Parâmetros Curriculares Nacionais" (PCNs). A pesquisa traz uma breve retrospectiva da educação no Brasil com o propósito de esclarecer como a situação do ensino de línguas chegou ao ponto em que se encontra hoje e faz uma reflexão sobre os aspectos teóricos dos Parâmetros Curriculares Nacionais de Língua Estrangeira para terceiro e quarto ciclos do ensino Fundamental, comparando essa teoria com a prática docente. Notou-se que, na teoria, o fazer docente tornou-se mais complexo, pois foi atribuído ao professor uma série de papéis e, na prática, ele ainda assume o papel de simples "transmissor" do conhecimento, como observado na análise dos relatórios de observação de estágio.

Palavras-chave: Curriculares Nacionais; Abordagem Sócio-interacional, Ensino Fundamental.

\section{Abstract \\ In 1998, the government launched a document called "Parametros Curriculares Nacionais", (PCNs), to help teachers make their teaching practice more meaningful and relevant. The document emphasises the importance of a sociointeractional approach when it comes to teaching a foreign language. This research paper looks into the theoretical aspects of the document and tries to analyse up to what extent primary and high school teachers are able to put into practice the suggested approach. A brief explanation of the development of the educational system in Brazil is given so that the reader can understand how the teaching of foreign languages has gotten to the point}


where it is nowadays. It reaches the conclusion that although the role of the teacher, in theory, has become more complex because it is expected that teachers take the part of facilitators and collaborators, when it comes to practice they still rely on the traditonal approach, transmitting skills and knowledge.

Keywords: asitem quunt, dolorro eate perum, voluptatium ent, que iusdaepudi. 


\section{Introdução}

A análise da sintonia entre teoria e a prática no ensino de língua inglesa nos parâmetros curriculares nacionais foi pautado por relatórios a partir da experiência docente e revelou que muitos dos alunos do curso de Letras Português/Inglês, e muitos dos professores observados por esses alunos, não se encaixam nesse perfil desejado pelo modelo proposto no modelo de ensino aprendizagem. São poucos os que dominam o idioma e percebeu-se que a maioria das aulas ainda está organizada de forma tradicional, em torno dos conteúdos, não apresentando coerência entre os objetivos e as necessidades dos alunos.

Um dos objetivos principais na sintonia entre teoria e a prática no ensino de língua inglesa nos parâmetros curriculares nacionais é demonstrar como o ensino do inglês é colocado em prática, e como o seu embasamento teórico é estudado durante os semestres do curso para que os futuros profissionais sintam-se seguros no exercício da profissão. Esta prática está apoiada nos PCNs - Parâmetros Curriculares Nacionais, por se tratarem de orientações gerais a respeito do básico a ser ensinado e aprendido no ensino fundamental e médio, elaboradas pelo próprio Ministério da Educação - MEC do país. Mas como se desenvolvem os PCNs? Vale a pena fazer uma breve retomada para melhor se entender esse processo.

A educação, no século XVIII, estava baseada no "modelo cartesiano" que se apoiava nas idéias do filósofo francês René Descartes, estabelecendo paradigmas para as diversas áreas do conhecimento e da vida humana. Acreditava-se que, se a natureza e o ser humano fossem divididos e estudados em pequenas partes, finalmente se entenderia o todo. Assim o conhecimento foi dividido em diversas disciplinas, estudadas separadamente. A formação de especialistas em cada uma das disciplinas favorecia estudos aprofundados e levava a descobertas que propiciaram condições para que muitos mistérios relacionados a fenômenos do universo, da matéria, da vida humana e dos seres vivos pudessem ser desvendados.

Apesar de colaborar comas descobertas e o progresso científico e tecnológico ocorridos no decorrer dos séculos, este modelo científico trouxe inúmeros inconvenientes, pois houve uma superespecialização, fazendo com que os estudiosos tivessem conhecimentos limitados sobre apenas um determinado assunto, uma vez que o fenômeno a ser estudado era isolado do todo.

\section{Transformando informações em conhecimento}

Para Morin (2000, p. 37) o conhecimento das informações ou dados isolados não fazem nenhum sentido, pois "a era planetária necessita situar tudo no contexto e no complexo planetário". O autor exemplifica como o significado da palavra "amor" adquire significados diferentes em cada contexto no qual é enunciado. Ele, ainda esclarece que o global (as relações entre o todo e as partes).

[...] é mais que o contexto, é o conjunto das diversas partes ligadas a ele de modo inter-retroativo ou organizacional. Dessa maneira, uma sociedade é mais que um contexto: é o todo organizador de que fazemos parte. O planeta Terra é mais do que um contexto: é o todo ao mesmo tempo organizador e desorganizador de que fazemos parte. O todo tem qualidades ou propriedades que não 
são encontradas nas partes, se estas estiverem isoladas uma das outras, e certas qualidades ou propriedades das partes podem ser inibidas pelas restrições provenientes do todo (MORIN, 2000:37).

Além do mais, acrescenta que o cidadão do novo milênio tem um sério problema, pois, somente por meio de uma reforma do pensamento ele conseguirá articular e organizar os conhecimentos como:

Reconhecer e conhecer os problemas do mundo; perceber e conceber a relação todo/partes. Para isso, a educação não pode apresentar os saberes desunidos, divididos, compartimentados, pois as "realidades ou problemas se apresentam cada vez mais multidisciplinares, transversais, multidimensionais, transnacionais, globais e planetários" (MORIN, 2000:36).

Porém, no século XVII, esta separação do conhecimento em disciplinas foi a mais adequada e aplicada na educação. Dessa maneira, as escolas passaram a dividir as aulas em momentos: um para desenvolver a mente, outro para aprender os conteúdos e outro momento para movimentar o corpo. Acreditava-se que, reduzindo a realidade em partes mais simples, a compreensão destas levaria à compreensão de sua totalidade. Os educadores apresentavam aos alunos o conteúdo de uma maneira distanciada da realidade concreta, separando o sujeito do objeto de conhecimento, fazendo com que a educação formal se distanciasse das reais necessidades, dos interesses e dos desejos dos educandos.

Araujo (2003:16) assinala que:

[...] desta forma, o aluno acaba deixando de ser considerado um ser complexo, que possui uma história de vida, traz conhecimentos específicos, possui desejos e emoções, e passa a ser conhecido como uma pessoa que aprende ou nãoaprende o conteúdo, e faz isto ou aquilo na sala de aula. (ARAUJO, 2003:16).

Muitas vezes, passa a ser tratado como um número em algumas escolas. É considerado dentro de um padrão de normalidade, que professores não saibam nada da vida de seus alunos. O que eles pensam, o que sentem com relação ao idioma, o que sentem, como veem a escola etc. - é a "abstração levada à dimensão das relações humanas. Segundo Araujo (2003:18)", na medida em que os avanços científicos foram sendo produzidos ao longo do século XX, notou-se que os pressupostos das áreas disciplinares tradicionais não conseguiam explicar a complexidade dos fenômenos estudados. Por essa razão, foi necessária buscar a união de especialistas de diferentes áreas, complementando saberes até então fragmentados.

Para estudar o genoma humano, por exemplo, tem sido necessária a colaboração de especialistas das áreas das ciências físicas, biológicas e humanas, reunidos num trabalho integrado. Isso mostra que as disciplinas isoladas, estruturadas a partir do paradigma cartesiano, não fazem mais sentido, pois não são suficientes para explicar os fenômenos da vida humana e da natureza em sua diversidade.

Embora o ensino tradicional, baseado no modelo cartesiano de explicar o mundo, já tenha perdido força teoricamente, no Brasil ele se encontra enraizado na prática dos professores. Vale apena, então, entender melhor o ensino tradicional, pois talvez a sua compreensão o possibilite "ultrapassálo ou fazê-lo melhor" (MIZUKAMI, 1986: 8).

Mizukami (1986) investigou a caracterização do ensino tradicional, bem como as implicações decorrentes dele para a 
ação pedagógica do professor. Nessa abordagem, $\mathrm{O}$ homem é considerado como inserido num mundo que irá conhecer através de informações que lhe serão fornecidas e que se decidiu serem as mais importantes e úteis para ele. É um receptor passivo até que, repleto das informações necessárias, pode repeti-las a outros que ainda não as possuam, assim como pode ser eficiente em sua profissão, quando de posse dessas informações e conteúdos. O ser humano no início de sua vida é considerado uma espécie de tabula rasa, na qual são impressas, progressivamente, imagens $\mathrm{e}$ informações fornecidas pelo ambiente na opinião de alguns pensadores educadores (MIZUKAMI, 1986:8).

\section{Confrontando modelos com ideais}

O mundo é externo ao indivíduo, como esclarece Mizukami (1986:9), o indivíduo vai, gradativamente, ampliando sua compreensão do mundo na medida em que se confrontam os modelos com os ideais. As aquisições científicas e tecnológicas, o exercício do raciocínio e as demonstrações na prática das teorias elaboradas através dos séculos comprovam que o aprendizado se dá nessa confluência conforme (MIZUKAMI, 1986):

Este tipo de ensino tem como objetivo perpetuar os valores apregoados pela sociedade e sua cultura. Também visa à produção de pessoas eficientes que consigam impulsionar a sociedade em direção a um maior domínio sobre a natureza, ampliando e aprofundando as áreas de conhecimento. Assim, os programas de ensino estão baseados nos níveis culturais que devem ser adquiridos pelos alunos em cada série. Caso o aluno não atinja o mínimo cultural exigido, ele é reprovado e o diploma passa a ser visto como um "instrumento de hierarquização dos indivíduos num contexto social" (MIZUKAMI, 1986:10).

Sobre o aspecto social, Mizukami (1986:10) explica que a sobrevivência, das gerações mais novas e das sociedades, se encontra vinculada às experiências e aquisições das gerações adultas. A autora ainda afirma que esta abordagem possui uma visão individualista do processo educacional e, portanto, não possibilita trabalhos de cooperação "nos quais o futuro cidadão possa experienciar a convergência de esforços".

O conhecimento é cumulativo e adquirido pelo indivíduo por meio de transmissão, ou seja, o ser humano deve ser capaz de incorporar informações sobre o mundo. Para facilitar essa incorporação, há uma decomposição da realidade, que, às vezes, leva a uma organização de um ensino dedutivo. Somente os resultados são apresentados aos alunos para que sejam armazenados, desconsiderando-se $\mathrm{O}$ processo. Desta forma, o sujeito (aluno) não tem participação ativa na elaboração e na aquisição do conhecimento; compete a ele memorizar definições, enunciados de leis, sínteses e resumos que lhe são fornecidos pelo professor.

Segundo Freire (1987:58), neste caso, tem-se uma concepção "bancária" da educação, pois [...] a única margem de ação que se oferece aos educandos é a de receberem os depósitos, guardá-los e arquivá-los [...] e, portanto não há criatividade, não há transformação, não há saber. Só existe saber na invenção, na reinvenção na busca inquieta, impaciente, permanente, que os homens fazem no mundo, com opondo e como os outros. A educação é entendida, portanto, como um produto e durante o período em que o aluno frequenta a escola, é confrontado com modelos que devem ser seguidos porque 
poderão ser úteis no futuro. Estes modelos já estão pré-estabelecidos através de ideias selecionadas e organizadas logicamente e, por isso, não existe a necessidade de se considerar o processo de aprendizagem na educação.

A escola, então, "é o local onde se realiza a educação, a qual se restringe, em sua maior parte, a um processo de transmissão de informações em sala de aula e funciona como uma agência sistematizadora de uma cultura complexa". (MIZUKAMI, 1986:12)

A relação social estabelecida é vertical, do alto para baixo, partindo do professor para o aluno. Cabe ao professor decidir tudo: metodologia, conteúdo, avaliação, forma de interação na aula, etc. Ele também deve conduzir e informar seus alunos quanto aos objetivos escolhidos pela escola ou sociedade em que vive. O professor exerce, então, o papel de mediador entre cada aluno e os modelos culturais, e uma vez que as tarefas a serem executadas pelos alunos exigem participação individual, as possibilidades de trabalho em pares ou grupos são reduzidas.

Para este tipo de abordagem, a aprendizagem consiste em aquisição de informações e demonstrações transmitidas pelo professor, que é o modelo pedagógico. Vale ressaltar um aspecto positivo desta abordagem: quando o professor domina o conteúdo e ministra uma aula expositiva de qualidade, o conhecimento é realmente transmitido e o aluno é poupado de horas de pesquisas desnecessárias. Porém, são formadas reações estereotipadas, de automatismos - hábitos -frequentemente isolados uns dos outros e aplicáveis somente às situações semelhantes em que foram adquiridos. Assim, o aluno que adquiriu o hábito - ou que "aprendeu" - tem apenas uma compreensão parcial, e dificilmente conseguirá transferir seus conhecimentos.
Este tipo de ensino dedica-se mais com a variedade e a quantidade de conceitos do que com a formação do pensamento reflexivo e crítico, existindo uma preocupação com a sistematização dos conhecimentos apresentados de forma acabada. As tarefas são padronizadas para se obter a fixação do conteúdo, recorre-se à rotina nos procedimentos didáticos.

\section{A metodologia da abordagem}

A metodologia, nesta abordagem, baseia-se nas aulas expositivas onde o professor traz o conteúdo pronto e o aluno limita-se a escutá-lo, passivamente. $\mathrm{O}$ ponto fundamental desse processo será o produto da aprendizagem. Se o aluno reproduzir automaticamente o conteúdo apresentado pelo professor, isso indicará que houve aprendizagem. $\mathrm{O}$ aluno limita-se a ouvir o professor e somente iniciará seu trabalho intelectual após a sua explicação, realizando os exercícios propostos (de repetição, aplicação e recapitulação). O professor, então, prossegue coma matéria "nova" e somente uma avaliação posterior mostrará se houve compreensão ou não.

Todos os alunos são tratados igualmente: o material didático e o ritmo de trabalho são os mesmos e, como só há espaço para a fala do professor, dificilmente saberá se algum aluno está necessitando de explicações adicionais. Quanto à avaliação, ela mede a quantidade e a exatidão de informações que o aluno consegue reproduzir. Conforme Mizukami (1986:17), "as notas funcionam, na sociedade, como níveis de aquisição do patrimônio cultural" por ela acumulado.

Embora muitas abordagens tenham surgido ao longo do século XX, nenhuma 
delas conseguiu sobrepor à abordagem tradicional na prática docente até os dias de hoje. Embora, não seja objetivo deste trabalho fazer um estudo aprofundado sobre as diversas abordagens de ensino, vale a pena fazer uma breve retomada a respeito das mais importantes para situar o leitor.

\subsection{Abordagem Comportamentalista}

Skinner pode ser considerado o representante desta abordagem que acredita que o homem é uma consequência das influências ou forças existentes no meio ambiente. "O conhecimento é uma 'descoberta' e esta é nova para o indivíduo que a faz. Mas, o que foi descoberto, já se encontrava na realidade anterior" (MIZUKAMI, 1986:19). Os comportamentalistas afirmam que certos acontecimentos se relacionam sucessivamente e consideram o conhecimento como resultado direto da experiência. Assim, a educação se preocupa em transmitir conhecimentos, comportamentos éticos, práticas sociais, habilidades consideradas básicas para a manipulação e controle do mundo/ambiente.

"O sistema educativo tem como finalidade básica promover mudanças nos indivíduos, mudanças estas desejáveis e relativamente permanentes, às quais implicam tanto a aquisição de novos comportamentos quanto à modificação dos já existentes" (MIZUKAMI, 1986:28). Desta forma, ensinam-se padrões de comportamento por meio de treinamento, que envolve um conjunto de técnicas diretamente aplicáveis em situações de sala de aula. Como consequência, o que não é programado como conteúdo, não é desejável e, é evitado.
Nesta abordagem, a ênfase está no produto obtido, assim como na abordagem tradicional, desta vez, porém, não em uma prática cristalizada através dos tempos, mas em resultados das experiências obtidas com o planejamento de contingências de reforço. Outro aspecto que diferencia esta abordagem da tradicional é a ênfase dada ao individual, embora seja apenas para se alcançar os comportamentos a que a disciplina ou o professor considerarem desejáveis. A avaliação é feita pelo professor e, ocorre no final do processo com o objetivo de verificar se os alunos adquiriram os comportamentos desejados.

\subsection{Abordagem humanista}

Conforme explica Mizukami, (1986), nesta abordagem, há uma ênfase no "eu", que inclui todas as percepções que $\mathrm{O}$ indivíduo tem da sua própria experiência, ou seja, uma das condições prioritárias para o desenvolvimento do indivíduo é o ambiente. $\mathrm{O}$ enfoque predominante desta teoria no Brasil é o de Carl Rogers. "Esta abordagem dá ênfase a relações interpessoais e ao crescimento que delas resulta, centrado no desenvolvimento da personalidade, do indivíduo, em seus processos de construção e organização pessoal da realidade, e em sua capacidade de atuar, como uma pessoa integrada" (MIZUKAMI, 1986: 38). Sendo assim, o ensino será centrado no aluno. Mizukami (1986:45) acrescenta que "tudo o que estiver a serviço do crescimento pessoal, interpessoal ou intergrupal é educação".

A escola, por sua vez, deve possibilitar a autonomia do aluno, respeitando-o, oferecendo condições para que ele se desenvolva. Como o ensino está centrado no ser humano, há que se descobrir meios ou técnicas de dirigir a pessoa à sua própria existência para que, desta forma, ela possa estruturar-se e agir. A competência básica do 
professor consiste, unicamente, na habilidade de compreender-se e compreender ao outro, assumindo a função de facilitador.

O aluno deve ser compreendido como um ser que se auto desenvolve e cujo processo de aprendizagem deve ser facilitado. Assim, nãoé possível determinar técnicas ou métodos para ensinar. Também, cabe ao aluno, assumir a responsabilidade de controlar sua própria aprendizagem, definindo e aplicando os critérios para avaliar se está atingindo os objetivos que pretende. Portanto, nessa abordagem, optase pela autoavaliação.

\subsection{Abordagem cognitivista}

Mizukami (1986:59) explica que as teorias cognitivistas se preocupam em estudar os "processos centrais" do indivíduo, os quais são dificilmente observáveis, como: organização do conhecimento, processamento de informações, estilos de pensamento, comportamentos relativos à tomada de decisões, etc. Além disso, estudam cientificamente a aprendizagem como sendo mais que um produto do meio ambiente, das pessoas ou de fatores externos aos alunos.

Mesmo que se note uma preocupação com as relações sociais, a ênfase é dada na capacidade do aluno de integrar informações e processá-las. Este tipo de abordagem é interacionista, já que o conhecimento é produto da interação entre $\mathrm{o}$ sujeito $\mathrm{e}$ objeto, sem ênfase em nenhum deles, ou seja, ambos possuem o mesmo grau de importância. A inteligência constrói-se a partir da troca do organismo com o meio, por meio das ações do indivíduo.

Dentre os maiores teóricos nessa perspectiva encontra-se Piaget que descreve o desenvolvimento do ser humano ao passar por fases que se inter-relacionam e se sucedem até que atinjam estágios da inteligência caracterizados por maior mobilidade e estabilidade. O conhecimento é considerado como uma construção contínua, pois ao passar pelas fases vão se formando novas estruturas que não existiam anteriormente no indivíduo. Mizukami aponta que:

O processo educacional tem um papel importante ao provocar situações desequilibradoras para os alunos (desequilibradoras adequados aos níveis em que os alunos se encontram), de forma que seja possível a construção progressiva das noções e operações, ao mesmo tempo em que a criança vive intensamente cada etapa de seu desenvolvimento (MIZUKAMI, 1986:70).

Assim, o objetivo da educação não consiste em seguir modelos ou transmitir verdades, informações, demonstrações, mas sim em ensinar o aluno a aprender, por si próprio, a conquistar essas verdades. A cooperação possui importante papel na abordagem, e não poderia existir na escola uma atividade intelectual baseada em ações. "Há investigações e pesquisas espontâneas, além de uma livre cooperação dos alunos entre si e não apenas entre professor e alunos" (MIZUKAMI, 1986:73).

O ensino compatível com esta teoria tem que admitir o erro, basear-se na pesquisa e na investigação, na solução de problemas por parte do aluno, no trabalho em grupos e na liberdade de ação. A aprendizagem verdadeira dá-se no exercício operacional da inteligência. Como consequência, a avaliação deve ser apoiada em múltiplos critérios, considerando-se principalmente a assimilação e a aplicação em situações variadas. 


\subsection{Abordagem sociocultural}

Nesta abordagem, destaca-se Paulo Freire, que considera o homem como sujeito da educação, "situado no tempo e no espaço, inserido num contexto sócio econômico, cultural e político, enfim, num contexto histórico" (MIZUKAMI, 1986:86). A elaboração e o desenvolvimento do conhecimento estão ligados ao processo de conscientização, onde o homem, ao refletir sobre sua realidade conscientiza-se e a modifica. Portanto, a educação se dá em um contexto, onde é fundamental que se supere a relação, opressor versus oprimido, na relação de ensino aprendizagem.

Essa superação exige condições tais como: reconhecer-se criticamente e solidarizar-se com o oprimido engajando-se na práxis libertadora, onde o diálogo exerce papel fundamental na percepção da realidade opressora. (MIZUKAMI, 1986:97). Deve haver, por parte do professor, uma preocupação com cada aluno, com o processo. Os alunos participam do processo de aprendizagem juntamente com o professor, onde o diálogo é essencial. Desse modo o processo de avaliação, consiste na auto avaliação e/ ou avaliação mútua e permanente da prática educativa por professor e aluno. (MIZUKAMI, 1986:97).

Como já mencionado, o tipo de abordagem ainda praticado pela maioria dos professores no sistema educacional brasileiro é o tradicional. A atual legislação educacional brasileira já adotou medidas para a implementação de um novo sistema de ensino, porém as resistências a esta implementação são enormes, pois como afirma Araujo (2003:23), "tem sido muito difícil romper a estrutura disciplinar em todo o sistema educacional".

O autor acredita que parte desta resistência é justificada pelos exames vestibulares. Estes se baseiam nas disciplinas tradicionais e, devido à forte seleção para o ingresso nas poucas vagas oferecidas nas universidades públicas e gratuitas, tais exames foram ficando cada vez mais fragmentados, especializados e exigentes em termos de quantidade de conteúdos. $\mathrm{Na}$ tentativa de auxiliar os professores a implementarem mudanças na sua prática docente, surgiram os PCNs, pois, frente às transformações científicas, econômicas, sociais e tecnológicas que estão acontecendo no mundo, não é mais possível uma educação tradicional.

Sabe-se que só consegue emprego quem tem uma boa formação escolar, pois estamos numa era marcada pela competição e pela excelência, quando a ciência e a tecnologia exigem dos jovens novas habilidades para ingressar no mundo do trabalho. Assim, o papel essencial da educação seria formar cidadãos com uma ampla visão ética, moral e social. Os conteúdos e o ensino das disciplinas exigiram adaptações, pois o conceito de cidadania atual é diferente daquele de dois mil anos atrás. Ocorre um problema que muitos não perceberam; o currículo, com tais conteúdos e disciplinas, exerce a função apenas de instruir os alunos e as alunas sobre os conhecimentos construídos historicamente pela humanidade. Não focam em formar eticamente o cidadão e a cidadã que vive nas sociedades contemporâneas (ARAUJO, 2003: 32).

$\mathrm{Na}$ edição especial da Revista Nova Escola (1998:4), o artigo "Parâmetros Curriculares Nacionais - Fáceis de entender" esclarece o papel desse documento como sendo "uma nova forma de educar alunos para o próximo milênio, aproximando o que se ensina na sala de aula do mundo tal como ele é nos dias de hoje". Assim, os PCNs se prestam a orientar o planejamento escolar, as ações de reorganização de currículos e as reuniões com professores e pais. Eles não 
são obrigatórios, e como afirma o Ministro da Educação de 1998, Paulo Renato Souza, na apresentação dos PCNs:

Os Parâmetros Curriculares Nacionais foram elaborados procurando de um lado respeitar, as diversidades regionais, culturais, políticas existentes no país e, de outro, considerar a necessidade de construir referências nacionais comuns ao processo educativo em todas as regiões brasileiras. Com isso, pretende-se criar condições, nas escolas, que permitam aos nossos jovens ter acesso ao conjunto de conhecimentos socialmente elaborados e reconhecidos como necessários ao exercício da cidadania. (PCN, 1998:3).

Todos os aspectos citados nos levam a inferir que os cursos de graduação em letras devam ter estruturas flexíveis. Essa flexibilidade deveria facultar ao profissional opções para se formar em áreas de conhecimento para atuação no mercado de trabalho. Isso criaria mais oportunidades para o desenvolvimento de habilidades necessárias para se atingir a competência desejada no âmbito profissional. Desta forma, a escolha dos Parâmetros Curriculares Nacionais para dar embasamento teórico à prática docente dos futuros professores de Língua Inglesa seria justificável.

Com relação à péssima qualidade das aulas de Inglês ministradas nas escolas públicas, partem constantes questionamentos dos alunos que serão os futuros professores. As leituras dos relatórios finais de estágio abordam, ou denunciam a falta de preparo didático pedagógico desses profissionais.

\section{Metodologia}

Buscando compreender até que ponto a prática docente dos professores de Língua
Inglesa na escola pública se aproxima do preconizado pelos PCNs, nesta pesquisa, foi solicitado aos alunos de $5^{\circ}$ e $6^{\circ}$ semestres do curso de Letras Inglês/Português que elaborasse relatórios de aprendizagem. Eles deveriam observar as aulas assistidas durante o período de estágio junto às escolas públicas e privadas de ensino fundamental da Grande São Paulo, no ano de 2005. A aplicação se deu em uma instituição de ensino Superior da Grande São Paulo, na disciplina de Prática de Ensino e Estágio Supervisionado de Língua Inglesa. A partir da elaboração dos relatórios e sua análise se pretende compreender, explicar e especificar o fenômeno para responder a questão central da pesquisa.

Considerando-se o objetivo deste trabalho, a pesquisa qualitativa etnográfica configura-se como a abordagem mais adequada. A presente pesquisa foi feita no ambiente natural em que ocorrem as ações dos professores, que é o contexto da sala de aula e tem o pesquisador como principal instrumento. Além disso, esse tipo de pesquisa trabalha com valores, crenças, hábitos, atitudes, representações e se adéqua a aprofundar a complexidade de fatos e processos particulares e específicos a indivíduos e grupos.

De acordo com Santos e Gamboa (2002, p. 43), o objetivo da pesquisa qualitativa é a compreensão ou interpretação do fenômeno social, com base nas perspectivas dos atores, por meio da participação em suas vidas. Seu propósito fundamental é a compreensão, explanação e especificação do fenômeno. Lüdke e André (1986) esclarecem que as escolhas e os métodos na etnografia se fazem de acordo com o problema e, de modo geral, desenvolvem-se em três etapas:

$1^{\circ}$ ) exploração: seleção e definição de problemas, escolha do local de estudo e contatos para imersão no campo, além das primeiras observações para 
familiarização com o fenômeno; $2^{\circ}$ ) decisão: busca sistemática dos dados que o pesquisador selecionou como mais importantes para compreender e interpretar o problema; $3^{\circ}$ ) descoberta: explicação da realidade e desenvolvimento de teorias (Lüdke e André, 1986, p. 16).

$O$ pesquisador, na pesquisa qualitativa, tenta compreender o significado que os outros dão às suas próprias ações segundo uma tarefa interpretativa. Isto é feito através da abordagem hermenêutica, ou seja, analisando cada ação dentro do contexto em que ela acontece:

[...] a compreensão de uma ação em particular requer a compreensão do significado-contexto no qual ela se dá e esta compreensão depende daquela ação particular. [...] o foco da pesquisa qualitativa é a experiência individual de situações, o senso comum, o processo diuturno de construção de significado, o como (SANTOS; GAMBOA, 2002:43).

Nesse sentido, a pesquisa levará em consideração as ações particulares referentes a cada contexto, ou seja, cada escola e seu respectivo professor com seu grupo de alunos, sabendo, no entanto, que a subjetividade na análise e interpretação dos resultados estará presente, como assim o permite a pesquisa qualitativa. Vale ressaltar que, subjetividade, neste contexto, deve ser entendida segundo a definição para a filosofia, na Língua Portuguesa de acordo com o dicionário HOUAISS (2010:2624) "realidade psíquica, emocional e cognitiva do ser humano, passível de manifestarem-se simultaneamente nos âmbitos individual e coletiva, e comprometida com a apropriação intelectual dos objetos externos".

De acordo com Nunan (1992) todo o conhecimento é relativo, já que nele há um elemento subjetivo que o torna único cada contexto de pesquisa, cujos resultados não podem ser generalizados para outras situações além daquelas em que os dados foram colhidos. Para isso, foi solicitado aos alunos-futuros professores que anotassem os seguintes itens em seus relatórios de observação:

- Tipo de escola: pública ou privada.

- Número de alunos em sala.

- Livro utilizado / material utilizado.

- Objetivo da aula.

- Habilidades desenvolvidas: oral / escrita / leitura / auditiva.

- Descrição detalhada da aula observada.

- Reflexão do aluno-futuro professor a respeito da abordagem de ensino, das técnicas, das atividades e qualquer outro aspecto relevante observado.

Finalmente, mais uma característica da pesquisa qualitativa etnográfica, que se ajusta ao objetivo deste trabalho, é relativa ao seu método:

[...] O indutivo partindo dos dados para a teoria, por definições que envolvem o processo e nele se concretizam, pela intuição e criatividade durante o processo da pesquisa. Por conceitos que se explicitam via propriedades e relações, pela síntese holística e análise comparativa e por uma amostra pequena escolhida seletivamente, $\mathrm{O}$ principal critério de pesquisa é a validade (SANTOS; GAMBOA, 2002, p.44, 45).

Sendo assim, argumenta-se que as conclusões na pesquisa etnográfica são subjetivas e muitos podem inadvertidamente considerá-la como sinônimo de pouco confiável. Para a pesquisa etnográfica, neutralidade não existe, qualquer observação 
pode ser interpretada distintamente por diferentes pesquisadores. $\mathrm{O}$ ponto de vista e o próprio modo de enxergar o objeto analisado são permeados por conhecimentos, sentidos e julgamentos de valor inerentes a ideologias pessoais, que é a idiossincrasia daquele que olha (MENEZES DE SOUZA; GRIGOLETTO, 1993). Isso pode acontecer quando há envolvimento direto e proposital do pesquisador na tarefa de pesquisar. Sendo assim, não somente as metodologias de base interpretativa, como as etnográficas, podem resultar em interpretações subjetivas. Com a finalidade de estabelecer confiabilidade em pesquisa de características etnográficas, este estudo segue sugestões de Lincoln e Guba (1980), atendendo aos critérios de credibilidade, transferência, dependência e confirmação ao:

- Fazer documentação detalhada e extensa da prática em foco: todos os relatórios de observação de estágio de alunos utilizados foram guardados;

- Confirmar a análise através de referenciais teóricos existentes na bibliografia, visando fundamentar os argumentos;

- Ter um contato próximo com o contexto da pesquisa: a pesquisadora $\mathrm{fez}$ parte do contexto, acompanhando e orientando seus alunos - estagiários, envolvendo-se diretamente em todo o processo;

- Deixar os dados disponíveis para reexame aos interessados que $O$ solicitarem: os dados foram devidamente arquivados e estão à disposição.

\section{Análise dos dados coletados}

Foram coletados dois relatórios de observação por aluno, perfazendo no total, 664 relatórios. Destes, 643 foram observações feitas em escolas públicas e 21, em escolas particulares. Para a presente pesquisa, reduziu-se, então, a amostra para 42 relatórios (Anexo 2), 50\% referentes a instituições públicas e os restantes a instituições privadas. O critério que norteou essa redução foi a de equilíbrio entre as duas amostras (21 escolas públicas e 21 escolas privadas).

As escolas públicas têm, em média, salas com 35- 40 alunos. Nenhum desses alunos possui livros ou apostilas para acompanhar as aulas. Essas escolas também não dispõem de materiais como toca $C D$, vídeo cassete ou computador. As escolas particulares têm, em média, de 15 a 20 alunos por sala, utilizam livros, ou apostilas de cursinhos renomados ou elaborados pelo próprio professor; e a escola também dispõe de equipamentos como toca $\mathrm{CD}$, vídeo cassete e computador para que o professor tenha as ferramentas necessárias em mãos para facilitar o processo de ensinoaprendizagem.

No caso das escolas públicas, o professor conta somente com giz e lousa para ministrar suas aulas. Isso, como se observa pelos relatos abaixo, faz com que se passe muito tempo da aula com cópia de textos e exercícios, não sobrando tempo para atividades mais produtivas e relevantes que tenham a finalidade de desenvolver habilidades e competência comunicativa. Tal problema, inclusive, já está previsto no documento oficial (PCN), prevenindo o professor e sugerindo que ele desenvolva somente uma habilidade: a de leitura.

É importante considerar as condições da sala de aula da maioria das escolas brasileiras. Com relação ao tempo e ao espaço, geralmente a carga horária é reduzida, as classes são superlotadas. É comum as escolas colocarem nas salas de aula professores com escasso domínio técnico e habilidades orais. $\mathrm{O}$ material didático é reduzido ao giz, livro didático, 
entre outros cursos imaginados pela criatividade do professor. Assim, inviabilizar o ensino das quatro habilidades comunicativas fica difícil. $O$ foco na leitura das Línguas Estrangeiras no país pode ser justificado em termos da função social e dos objetivos realizáveis, tendo em vista as condições existentes apontadas (PCN, 1998:20).

As observações apresentadas por Menezes (2003) apontam para uma justificativa conformista.

É surrealista que um documento do próprio MEC reafirme a má condição do ensino no país e que se acomode a essa situação adversa em vez de propor políticas de qualificação docente e de melhoria. [...] O texto dos PCN, deveria enfatizar a necessidade de se criarem condições para que a obrigatoriedade do ensino na LDB de 1996. As necessidades de mudança nas condições de seu ensino alteram o contexto adverso gerado pela legislação anterior e fornece justificativas para a não realização do enunciado (MENEZES, 2003:3).

Isto demonstra que o ensino de idiomas no Brasil, ainda é visto como algo pouco relevante. Menezes, no mesmo artigo, chama a atenção para o fato de que o texto dos PCNs nega a importância das habilidades orais e de escrita. Deve-se conhecer uma Língua Estrangeira não só para ler documentos, mas também para interagir com falantes na modalidade oral ou escrita, em função da presença da internet e do contexto globalizado em que vivemos.

Além disso, a Constituição Federal do Brasil, no artigo 205, garante a educação como direito de todos e dever do Estado e da família, será promovida e incentivada com a colaboração da sociedade, visando ao pleno desenvolvimento da pessoa, seu preparo para o exercício da cidadania e sua qualificação para o trabalho. Ter qualificação para o trabalho, no que se refere à Língua Estrangeira, inclui ter domínio das quatro habilidades e, como bem lembra Menezes (2003).

"Ao abrir os jornais, veremos nos classificados, a procura é por profissionais que falem a língua. Nunca vi um anúncio procura alguém que leia em inglês, mas que fale inglês. Isso pressupõe conhecer essa língua como língua viva e não como uma língua morta com seus textos escritos" (Menezes, 2003, p 4).

$\mathrm{O}$ próprio documento (PCN) reconhece essa colocação quando, na página 20 , enumera as várias situações em que a Língua Estrangeira será fundamental. Entre essas situações estão exemplos que demandarão as diversas habilidades: consulta a classificados, redação de currículos, entrevistas para emprego, compreender melhor filmes etc. Menezes (2003:5) demonstra que o documento apresenta uma série de contradições "que ora reconhecem e enfatizam a importância do ensino de línguas e ora criam barreiras para seu ensino efetivo". De qualquer modo, com contradições ou não no documento, na sala de aula, o professor deve transformar os alunos em usuários competentes de uma Língua Estrangeira.

Nos relatórios analisados, percebe-se que nas descrições das aulas observadas, os professores estão, no máximo, ensinando algumas estruturas gramaticais e um vocabulário de uso cotidiano. Frases soltas, descontextualizadas, sem uso prático na vida real. As atividades elaboradas não desenvolveram nenhuma habilidade comunicativa, revelando que os professores de hoje ainda reproduzem os modelos do século passado. A abordagem de ensino predominante em nossas escolas, seja ela pública ou privada, ainda é a tradicional 
gramática-tradução: “O ensino, em todas as suas formas, nessa abordagem, será centrado no professor. Esse tipo de ensino volta-se para o que é externo do aluno: o programa, as disciplinas, o professor. $\mathrm{O}$ aluno apenas executa as prescrições que lhe são fixadas por autoridades exteriores" (MIZUKAMI, 1986:8).

Os Parâmetros Curriculares Nacionais (PCNs) têm sido motivo de polêmica entre os educadores e os estudiosos do meio acadêmico. Parece que a palavra "parâmetro" vem sendo interpretada erroneamente por alguns que a entendem como uma série de orientações que devem ser seguidas como modelo padrão Porém, ao buscarmos o significado dessa palavra no dicionário, encontraremos a seguinte definição: princípio ou norma que se deve ter em conta na estruturação de um problema ou sistema (HOUAISS, 2001:2120.). Portanto, o documento elaborado pelo MEC, "Os Parâmetros Curriculares Nacionais" são orientações gerais sobre o básico a ser aprendido em cada etapa. Os professores devem adaptar os parâmetros à realidade de suas escolas, de acordo com a região e necessidades específicas.

$\mathrm{O}$ que se percebeu, no decorrer desta pesquisa, é que o texto dos PCNs de Língua Estrangeira exige um conhecimento muito profundo a respeito das concepções teóricas do processo de ensino e aprendizagem, uma vez que elas são brevemente mencionadas. Também, para o tipo de abordagem sócio interacional, é fundamental o domínio fluente do idioma. Sabe-se que os cursos que oferecem Licenciatura dupla, Português e Inglês. Em sua maioria, os cursos teem a duração de três anos, com uma carga horária de aproximadamente 3.000 horas. Esse tempo não é suficiente se analisado em relação à complexidade das habilidades linguísticas e pedagógicas esperadas de um futuro professor de Língua Estrangeira.
Os documentos - os PCNs e as Diretrizes Curriculares para os Cursos de Letras (2001) realmente apresentam e defendem aspectos teóricos, muito bem elaborados, porém inadequados para a realidade da nossa educação. De acordo com as diretrizes, os profissionais em Letras devem:

$$
\begin{aligned}
& \text { "ter domínio do uso da língua ou das } \\
& \text { línguas que sejam objeto de seus } \\
& \text { estudos, em termos de sua estrutura, } \\
& \text { funcionamento e manifestações } \\
& \text { culturais"13. Deles se espera múltiplas } \\
& \text { competências e habilidades para } \\
& \text { atuarem como "professores, } \\
& \text { pesquisadores, críticos literários, } \\
& \text { tradutores, intérpretes, revisores de } \\
& \text { textos, roteiristas, secretários, } \\
& \text { assessores culturais, entre outras } \\
& \text { atividades". }
\end{aligned}
$$

Dentre as múltiplas competências listadas, o professor de língua inglesa deve no mínimo ter:

- Domínio dos conteúdos básicos que são objeto dos processos de ensino e aprendizagem no ensino fundamental e médio;

- Domínio dos métodos e técnicas pedagógicas que permitam a transposição dos conhecimentos para os diferentes níveis de ensino;

- A capacidade de resolver problemas, tomar decisões, trabalhar em equipe e comunicar-se dentro da multidisciplinaridade dos diversos saberes que compõem a formação universitária em Letras.

\section{Considerações Finais}

A análise dos relatórios e da experiência docente revela que muitos dos alunos do $5^{\circ}$ e $6^{\circ}$ semestres do curso de Letras Português/Inglês, e muitos dos professores 
observados por esses alunos durante o estágio, não se encaixam nesse perfil. São poucos os que dominam o idioma $\mathrm{e}$ percebeu-se que a maioria das aulas ainda está organizada de forma tradicional, em torno de conteúdos, não apresentando coerência entre os objetivos e as necessidades dos alunos. O próprio ensino superior ainda está estruturado dessa maneira. Como conseguir formar professores para lecionar usando a abordagem sócio interacionista, se o modelo que eles têm, ou tiveram como alunos, é outro?

É imprescindível dar ao futuro professor uma formação de qualidade. Isso demanda um investimento na capacitação teórica que o possibilite a compreender a forma como o conhecimento científico é produzido no seu campo do saber. Avaliar criticamente esta produção de conhecimento e de atuar segundo a orientação crítica deste conhecimento. É necessário que o professor seja capaz de investigar e criticar sua própria atuação em sala de aula e de sugerir mudanças necessárias, embasado em um conhecimento teórico relevante. Alguns dos cursos livres de idiomas em que a pesquisadora já atuou têm essa preocupação. Essas instituições têm objetivos claros e bem definidos no que se refere ao que se espera do professor e aos princípios pedagógicos. A partir daí, são oferecidos treinamentos e cursos dentro da própria escola, com o objetivo de transformar a prática dos professores. Parece que essa realidade não é compartilhada pelas escolas de ensino fundamental e médio.

Os PCNs foram lançados na teoria, mas não houve uma preocupação em oferecer estudo e treinamento adequado nas escolas para os professores. Não se trata de aprender a lidar com um equipamento, cujo manual de instruções, resolve eventuais problemas que venham a ocorrer, seguindo uma série de etapas pré- determinadas, para atingir o objetivo desejado. Trata-se de uma mudança de visão de mundo, de hábitos educacionais. Essa abordagem tornou $\mathrm{O}$ fazer docente mais complexo, atribuindo ao professor uma série de papéis diferenciados: colaborador, facilitador, incentivador e avaliador do processo de aprendizagem. Porém, essa nova perspectiva com a mudança de papéis, desde o de "transmissor" para o de "colaborador", só se deu na teoria.

Pelos relatórios de observação de estágio, notou-se que na prática, nossos professores ainda são aqueles que transmitem o conhecimento. Fica claro, portanto, que se não houver uma mudança no sistema de formação de professores, o quadro continuará o mesmo por muitos anos e, o ensino do Inglês como Língua Estrangeira continuará dependendo dos cursos livres. É triste a realidade do estudante brasileiro que, num mundo globalizado, e estudando Inglês durante oito anos, não fala e nem mesmo compreende essa segunda língua.

\section{Referências Bibliográficas}

1. AlBUQUERQUE, E. Dificuldades de Leitura em Enunciados de Problemas de Matemática. Dissertação de Mestrado. Universidade Federal do Rio de Janeiro, Rio de Janeiro, 1993.

2. ALEXANDER, L.G. Look, Listen and Learn. London: Longman, 1968.

3. AQUINO, J. Groppa. Indisciplina: o contraponto das escolas democráticas. São Paulo: Moderna, 2003.

4. ARAÚJO, U. F. de temas transversais e a estratégia de projetos. São Paulo: Moderna, 2003. 
5. BRASIL. Lei $n^{\circ} 9.394$ de 20 de dezembro de 1996. S. IV arts.35. Estabelece as Diretrizes e Bases da Educação Nacional para o ensino médio. Em: http://www.aspuv.org.br/LDBE.htm. Acesso 20/01/ 2006.

6. CHAGAS, R. V. C. Didática especial de línguas modernas. São Paulo: Companhia Ed. Nacional, 1957.

7. DECLARAÇÃO UNIVERSAL DOS DIREITOS LINGÜISTICOS. Barcelona. 1996. Disponível em: http://www.amigosdolivro.com.br/noticias. php? $\operatorname{codNt}=190 \&$ rnd $=705>$ Acesso em 10março. 2006.

8. FREIRE, Paulo. Pedagogia do oprimido. $17^{a}$ ed. Rio de Janeiro: Paz e Terra., 1987.

9. saberes necessários à prática educativa. São Paulo: Paz e Terra, 1996.

10. HARMER, Jeremy. How to teach English. England: Addison Wesley Longman Limited, 2003.

11. HOBSBAWM, Eric. A era dos extremos. São Paulo: Companhia das Letras, 1999.

12. HOUAISS, Antonio. Dicionário da Língua Portuguesa. $1^{\mathrm{a}}$ ed. Rio de Janeiro: Objetiva, 2001.

\section{INSTITUTO NACIONAL DE ENSINO E PESQUISAS} EDUCACIONAIS. (1999). Exame Nacional do Ensino Médio: Documento Básico 2000. Brasilia: INEP.

14. KRASHEN, Stephen D. Principles and Practice in Second Language Acquisition. English Language Teaching series. London: Prentice-Hall International (UK) Ltd, 1981.

15. LARSEN-FREEMAN, D. Techniques and parinciples in language teaching. London: Oxford Press. 1986
16. LEFFA, Vilson J. O ensino de Línguas Estrangeiras no contexto nacional. Contexturas, APLIESP, 1999.

17. Metodologia do ensino de línguas. In BOHN, H. I.; VANDRESEN, P. Tópicos em linguística aplicada: $\mathrm{O}$ ensino de Línguas Estrangeiras. Florianópolis: Ed. UFSC, 1998:211. Em: http://www.leffa. pro.br/Metodologia_ensino_linguas.htm

18. LEGISLAÇÃO DO ENSINO SUPERIOR 2001. PARECER N $\mathrm{N}^{\circ}$ : CNE / CES 492/2001. Disponível em http://www.abmes.org.br/Legislacao/2001 /Parecer/Par_CES_492_Diretrizes_ Curriculares. Em 14/12/04.

19. LINCOLN, Y. S \& GUBA, E.G. Establishing trustworthiness. In Naturalistic inquiry. BH: Sage P., 1980.

20. LOPES, Moita. L.P. Oficina de Linguística Aplicada: A natureza social e educacional dos processos de ensinoaprendizagem de línguas. Campinas: Mercados de Letras, 1996 p 127 a134.

21. LORENZONI, I. Espanhol será obrigatório no ensino médio. Brasília: Portal MEC, 2005. Disponível em http://www.abrelivros.org.br/abrelivros/tex to.asp?id=1310. Acesso em 20/01/06.

22. LÜDKE, M. A, Marli E. D. A. Pesquisa em Educação: abordagens qualitativas. São Paulo: EPU, (Temas Básicos de Educação e Ensino) Texto: Pesquisa em Educação: Abordagens qualitativas. 1986.

23. MENEZES, V. A LDB e a legislação vigente sobre $\mathrm{o}$ ensino e a formação de professor de língua inglesa. 2003. Disponível em:

http://www.veramenezes.com/ensino..htm. Acesso em 04 jan 2006.

24. MENEZES DE SOUZA, L. M.; GRIGOLETTO, M. Towards autonomy in teacher education: bridging the gap between 
the university and the secondary state school. In autonomy in Language Learning. Porto Alegre: Editora da UFRGS, 1993.

25. MIZUKAMI, M. da Graça Nicoletti. Ensino: as abordagens do processo. São Paulo. EPU, 1986.

26. MORIN, Edgar. Os sete saberes necessários à educação do futuro/tradução de Catarina Eleonora F. da Silva e Jeanne Sawaya; revisão técnica de Edgard de Assis Carvalho. São Paulo: Cortez; Brasília, 2000.

27. NUNAN, D. Research Methods in Language teaching. Cambridge: C. University Press, 1992.

28. O'NEIL et al. Kernel Lessons Intermediate. London: Longman, 1975.

29. PARÂMETROS CURRICULARES NACIONAIS: TERCEIRO E QUARTO CICLOS DOENSINO FUNDAMENTAL / LÍNGUA ESTRANGEIRA /Secretaria de Educação Fundamental. Brasília: 1998.

30. REVISTA NOVA ESCOLA. São Paulo: Ed. Abril, edição 176, outubro 2004.
31. SANTOS FILHO, José Camilo dos; GAMBOA, Silvio Sanchez Pesquisa educacional: quantidade-qualidade. José Camilo dos Santos Filho; (org.) - 5. Ed. São Paulo: Cortez, 2002.

32. SAYÃO, Rosely. Educar para a autonomia. São Paulo, 2003. Disponível em: http//www.folha.uol.com.br

/fsp/equilibrio/eq. Acesso em 14 dez. 2004.

33. TRAVAGLIA, Luiz Carlos. Gramática e interação: uma proposta para o ensino de gramática no $1^{\circ}$ e $2^{\circ}$ graus. $8^{a}$ Ed. São Paulo: Cortez, 2002.

34. UNIVERSIDADE PRESBITERIANA MACKENZIE. Apresentação de trabalhos acadêmicos: guia para alunos do Mackenzie. 3.ed São Paulo: Ed Mackenzie, 2004.

35. WILLIAMS, Marion; BURDEN, L. R. Psychology for language Teachers. Cambridge: Cambridge 1997.

36. WILLIS, Jane; WILLIS Dave.Cobuild English Course Book 1. London: Collins, 1988Ate voluptatur aceperc hitasi invenda quo cones et hil mil idemquam, saes 